\title{
Static Series Compensator for the compensation of voltage-quality disturbances based on particle swarm optimization techniques
}

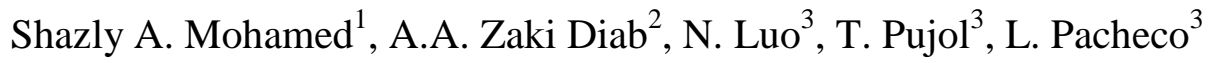 \\ ${ }^{1}$ Department of Electrical Engineering, Faculty of Engineering, South Valley University, Qena, Egypt. \\ ${ }^{2}$ Department of Electrical Engineering, Minia University, Minia, Egypt. \\ ${ }^{3}$ Polytechnic School, University of Girona, Campus Montilivi, 17071 Girona, Spain. \\ Corresponding author: N. Luo, phone number: +0034 656475276, e-mail: ningsu.luo@udg.edu
}

\begin{abstract}
Static Series Compensator (SSC) is a power electronic based device that provides three-phase controllable voltage source to restore the load voltage to pre-sag conditions within few milliseconds. This paper proposes a new control technique based on an adaptive tunning PI controller that uses a selective controller to describe the effectiveness of SSC for mitigating voltage sags in power distribution systems at critical loads. The integral of time multiply squared error (ITSE) index is minimized to reach the optimal tuning of PI controllers based on particle swarm optimization (PSO) technique to determine whether the best fitting solution is achieved. The controller is designed in a synchronously-rotating reference frame. Independent (homopolar component, d-axis component and qaxis component) controllers are used to tackle balanced and unbalanced voltage supplies. Simulation is done using Simulink "SimPowerSystem" Toolbox to illustrate the principle and performance of an SSC operation in load voltage compensation.
\end{abstract}

\section{Keywords}

Static series compensator, voltage sags, particle swarm optimization, voltage source converter, control system.

\section{Introduction}

Power quality is a very important issue due to its impact on electricity suppliers, equipment manufactures and customers [1-2]. An important percentage of all power quality problems is of the voltage-quality type. Voltage sag is a momentary decrease in the RMS voltage magnitude in the range of 0.1 to $0.9 \mathrm{pu}$, with a duration ranging from half cycle up to $1 \mathrm{~min}$. It is considered as the most serious problem of power quality, caused by the balanced or unbalanced faults in the distribution system or by the starting of large induction motors [3]. Among many different ways to mitigate voltage sags in power systems, the distribution static compensator and the SSC are the most effective devices; both of them based on the voltage source converter (VSC) principle [4]. SSC is a series-connected solid-state device that injects voltage into the system in order to regulate the load side voltage.
It is normally installed in a distribution system between the supply and a critical load feeder at the so-called Point of Common Coupling (PCC) which is defined as the point of the network changes [5-6]. The primary function of SCC is to rapidly boost up the load-side voltage in the event of voltage sag in order to avoid any power disruption to that load. In addition to voltage sags and swells compensation, SSC can also have other features such as harmonic compensation, power factor correction and reduction of transients in voltage and fault current limitations [7-8].

There are various circuit topologies and control schemes that can be used to implement SSC [9-10]. PID control, Genetic Algorithm, fuzzy based approach are used to accommodate the response speed and overshoot [11-15]. In [16-17] design methods using the PSO algorithm are presented for determining the optimal PID controller parameters. In [18] a self-tuning PI controller is proposed to adjust controller gains using the PSO technique for a static synchronous compensator, in which an efficient formula for the estimation of system load impedance using real-time measurements is derived.

In this paper, a traditional two-level, three-phase pulse width modulation (PWM) inverter is used. In order to improve the effectiveness of SSC for mitigating voltage sags in power distribution systems at critical loads, PSO techniques are used for achieving the optimal tuning of the PI controller parameters. The proposed ontrol system is tested in different fault situations such as single, double, three-phase faults in order to validate the PSO based controller. The simulation results will show the performance of the proposed control algorithm.

\section{SSC System}

The SSC can compensate voltage sags by means of the injection of the inverter voltage through the series connected transformer [19]. Figure 1 depicts a SSC 
system with a series insertion transformer connected between the distribution transformer and the sensitive load. The electrical system viewed from the PCC is modeled as a three-phase voltage source with a shortcircuit impedance. Essentially, the SSC consists of a series-connected injection transformer, a voltage source inverter (VSI), a filter capacitor and an energy-storage device connected to the inverter DC link.

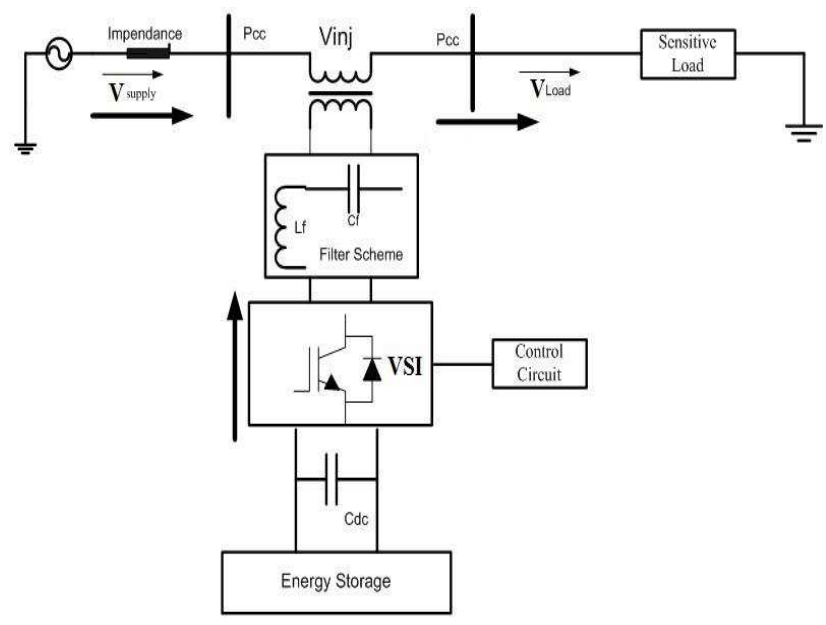

Fig. 1. Schematic diagram of a SSC system

The single-phase circuit shows that the SSC is nothing but a series voltage compensator [11]. Figure 2 shows the single-phase equivalent circuit used for studying the transfer function between the SSC inverter voltage $V_{S S C}$ and the sensitive-load voltage $V_{L}$, where $L_{T}$, and $R_{T}$, represent the leakage inductance of the transformer and its equivalent series resistance, respectively. $C_{f}$ is added to make a second-order filter together with $L_{T}$, in order to filter the inverter output voltage. The voltage supply has been represented by a voltage source $V_{S}$ with a shortcircuit impedance $R_{s h}$ and $L_{s h}$ in series with a distribution transformer represented by its leakage inductance $L_{T}$ and an equivalent resistance $R_{T}$. The sensitive load has been modeled by a parallel-connected R-L, the magnetizing branch of the transformer has been neglected. Finally, an additional load $Z_{P}$ has been added after the distribution transformer.

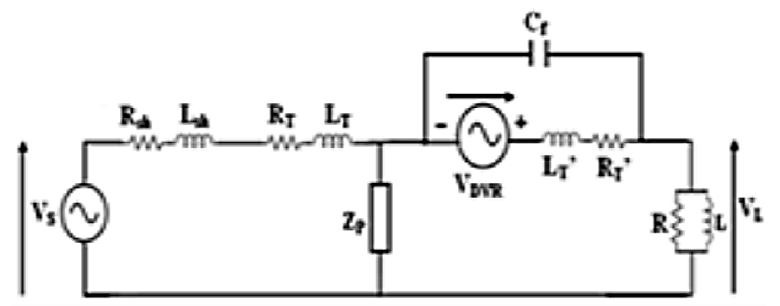

Fig. 2. Single-phase equivalent circuit of a SSC system

Figure 3 shows the frequency response for the SSC without the additional load $Z_{P}$ (only sensitive load) and a very strong power supply is used (short circuit power = $20 \mathrm{pu}$ ), this result also holds when the source shortcircuit power changes.
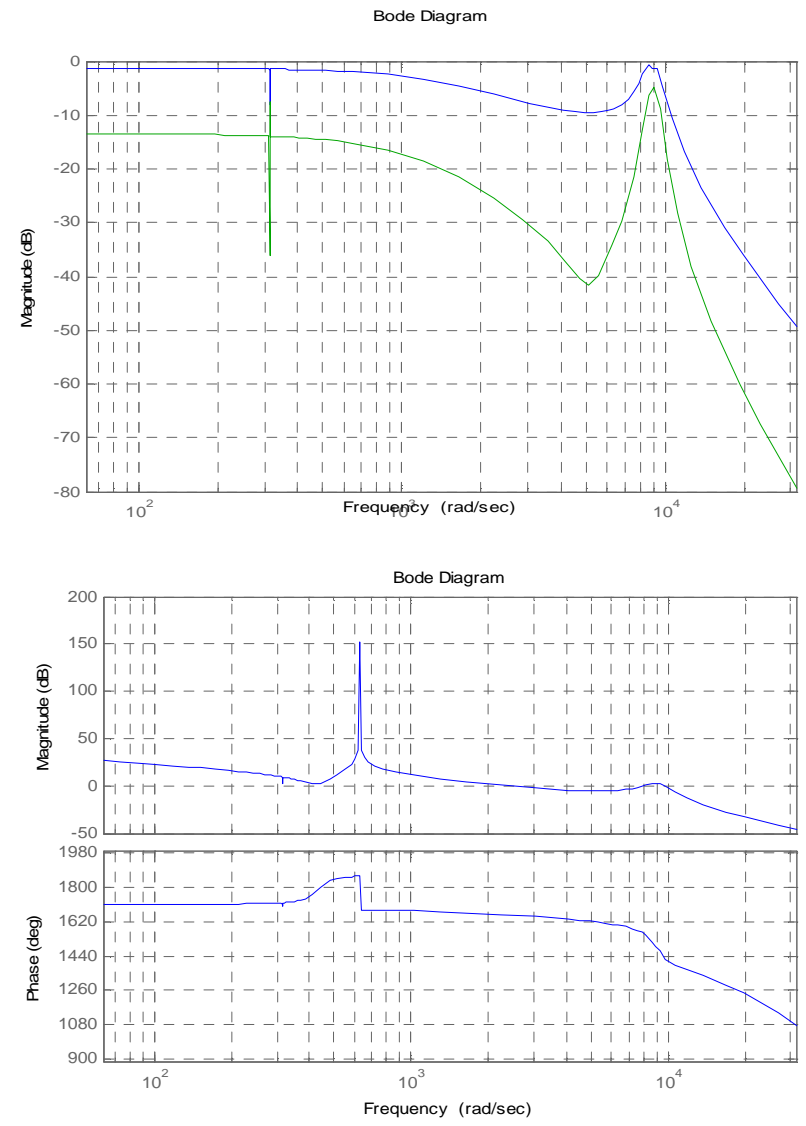

Fig. 3. Frequency Response for SSC system

\section{PSO Methodology and Algorithm}

In this work, the objective function to obtain the optimal values of $K_{p}$ and $K_{i}$ of the PI controller, which lead to the minimum ITSE, is calculated as follows [1]:

$$
\begin{aligned}
& \operatorname{ITSE}_{d}=\int_{0}^{\infty} t \cdot \text { error }_{d}^{2} d t \\
& \operatorname{ITSE}_{q}=\int_{0}^{\infty} t \cdot \text { error }_{q}^{2} d t \\
& I T S E=I T S E_{d}+\text { ITSE }_{q}
\end{aligned}
$$

where error $_{d}$ and error $_{q}$ are errors in load voltage of dcomponent and q-component, respectively.

The objective function to minimize ITSE is determined as follows:

$$
\begin{aligned}
\text { Minimize } & \left\{\operatorname{ITSE}\left(K_{p}, K_{i}\right)\right\} \\
\text { subject to } & 0 \leq K_{p} \leq 100,0 \leq K_{i} \leq 10
\end{aligned}
$$

PSO algorithm used for minimizing ITSE begins by: 1) Create the initial particles and assigning them initial velocities; 2) Evaluate the objective function at each particle location and determine the best (lowest) function value and the best location; 3) Choose new velocities, based on the current velocity, individual best locations for the particles and the best locations of their neighbors; 4) Update iteratively the particle locations (the new location is the old one plus the velocity, modified to keep particles within bounds), velocities, and neighbors. 
Iterations proceed until the algorithm reaches a stopping criterion.

For a dimensional search space, the position of particle $p$ is given by the following vector:

$$
Z_{p}=\left(Z_{p 1}, Z_{p 2}, \ldots, Z_{p n}\right)
$$

The velocity of particle $p$ is given by the following vector:

$$
V_{p}=\left(V_{p 1}, V_{p 2}, \ldots, V_{p n}\right)
$$

with $n$ being the number of the swarm particles, $V_{p}$ the velocity vector of particles and $Z_{p}$ the position vector of particles.

$$
\begin{aligned}
& \hat{g}_{j} \in\left\{g_{0}\left(t_{i}\right), g_{1}\left(t_{i}\right), \ldots g_{n}\left(t_{i}\right)\right\} \mid \operatorname{obj}\left(\hat{g}\left(t_{i}\right)\right) \\
& =\min \left\{\operatorname{obj}\left(g_{0}\left(t_{i}\right)\right), \operatorname{obj}\left(g_{1}\left(t_{i}\right)\right), \ldots, \operatorname{obj}\left(g_{n}\left(t_{i}\right)\right)\right\}
\end{aligned}
$$

where:

$g_{p} \quad$ Personal best position ever found by a particle $p$.

$g_{p}\left(t_{i}\right)$ Personal best position of particle $p$ at the time $t_{i}$ and it is called (Pbest).

$\hat{g}_{j} \quad$ Global position in which the objective function obj achieves its minimum value.

$\hat{g}_{j}\left(t_{i}\right)$ Global best position ever found by the swarm at time $\mathrm{t}_{\mathrm{i}}$ and it is called (gbest).

The velocity update of particle $\mathrm{p}$ is given by:

$$
\begin{aligned}
v_{p, j}\left(t_{i}+1\right)= & v_{p, j}\left(t_{i}\right)+c_{1} \cdot r_{1, j}\left(t_{i}\right) \cdot\left\lfloor g_{p, j}\left(t_{i}\right)-z_{p, j}\left(t_{i}\right)\right\rfloor \\
& +c_{2} \cdot r_{2, j}\left(t_{i}\right) \cdot\left\lfloor\hat{g}_{j}\left(t_{i}\right)-z_{p, j}\left(t_{i}\right)\right\rfloor
\end{aligned}
$$

where:

$z_{p, j}\left(t_{i}\right) \quad$ Position of the particle $j$ at time $\mathrm{t}_{\mathrm{i}}$.

$v_{p, j}\left(t_{i}\right) \quad$ Velocity of the particle $j$ at time $\mathrm{t}_{\mathrm{i}}$.

$v_{p, j}\left(t_{i}+1\right) \quad$ New velocity of the particle $j$ at time $\mathrm{t}_{\mathrm{i}}+1$.

$r_{1}, r_{2} \quad$ Independent random numbers from the interval $[0,1]$.

$c_{1}, c_{2}$ : Acceleration coefficients and equals to 2 .

Each particle $p$, because of its velocity, obtains a new position, which depends on its previous position and velocity:

$$
z_{p}\left(t_{i}+1\right)=z_{p}\left(t_{i}\right)+v_{p}\left(t_{i}+1\right)
$$

where $z_{p}\left(t_{i}+1\right)$ is the position of the particle $j$ at $\mathrm{t}_{\mathrm{i}}+1$.

In the global best model, all the particles of the swarm are defined as a neighbour of a particle $p$. Each particle can be influenced by any of other particles. The presentation of the swarm in this case can be made by a star topology. The equations for $\hat{g}\left(t_{i}\right)$ and $v_{p, j}\left(t_{i}\right)$ of gbest model are given by Eqs. (8) and (9) respectively. The PSO algorithm with inertia weight is given by [16]:

$$
\begin{aligned}
v_{p, j}\left(t_{i}+1\right)= & \omega \cdot v_{p, j}\left(t_{i}\right)+c_{1} \cdot r_{1, j}\left(t_{i}\right) \cdot\left\lfloor g_{p, j}\left(t_{i}\right)-z_{p, j}\left(t_{i}\right)\right\rfloor \\
& +c_{2} \cdot r_{2, j}\left(t_{i}\right) \cdot\left\lfloor\hat{g}_{j}\left(t_{i}\right)-z_{p, j}\left(t_{i}\right)\right\rfloor
\end{aligned}
$$

where:

$$
\omega=\omega_{\max }-\frac{\omega_{\max }-\omega_{\min }}{\text { Iter }_{\max }} \times \text { Iter }
$$

Iter: Iteration number.

Iter $_{\text {max }}$ : Maximum iteration number.

$\omega_{\max }: \quad$ Initial weights.

$\omega_{\min }: \quad$ Final weights.

It was demonstrated that 0.9 for $\omega_{\max }$ and 0.4 for $\omega_{\min }$ can greatly improve the performance of PSO [15]. This algorithm runs the Simulink model in each time of evaluating the objective function and the simulation time equals the transient time of the system ( 0.1 second). The steps of the gbest PSO algorithm are applied as follows:

Step 1. Initialization.

Step 2. Velocity and position update.

Step 3. Update of the pbest and gbest.

Step 4. Go to Step 2 until satisfying stopping criteria which is relative change in the best objective function value gbest over the last 20 iterations is less than 1e-99.

The detailed implementation strategies of the gbest PSO algorithm are described and the flow chart is presented in the following algorithm.

Load Simulink model, maximum iterations $\left(\right.$ Iter $\left._{\max }\right)=500$ and Population size $(\mathrm{j})=30$.

Initial each particle $\left(K_{p}, K_{i}\right)$ of population for objective function of Eq. 4.

Initial the personal best position (Pbest) for each particle of population.

Evaluate the objective function of Eq. 4 (ITSE) for each particle of population.

Set iteration counter Iter $_{\max }=1$.

$\underline{\text { While }}$ (stopping criteria does not achieved or Iter $\left._{\max } \leq 500\right) \underline{\mathrm{Do}}$ Determine the global best position ever found by the swarm (gbest), based on Eq. 8 .

Set iteration counter $j=1$.

$\underline{\text { While }}(\mathrm{j} \leq 50) \underline{\text { Do }}$

Determine the velocity for each particle of population, based on Eq. 9.

Determine the new position of particle, based on Eq. 10 .

$\underline{\boldsymbol{I F}}$ (new position in agreement with the constraints of Eq. 5)

Re-evaluate the objective function of Eq. 4 (ITSE), for each particle's new position.

Update the particle position.

$\underline{\boldsymbol{I F}}$ (evaluation of new position < Pbest)

Update best position (Pbest).

END IF

$$
\text { Set } j=\mathrm{j}+1
$$

END IF

End While

\section{End While}

$$
\text { Set } \text { Iter }_{\text {max }}=\text { Iter }_{\text {max }}+1
$$

Determine the global best particle, based on Eq. 8 . 


\section{Application of PSO for SSC}

The nonlinearity behaviour of each component in the three-phase voltage regulator's power circuit is considered and implemented in time domain based on the MATLAB Simulink's power system library and is taken as the objective function of Eq. 4. Designed computer programs based on MATLAB programing are prepared to find the optimal tuning parameters of PI controller of three-phase voltage regulator converter based on PSO algorithm.

Constant values of reference load voltage and reference load frequency are set. Optimal parametric values of PI controller for SSC are found by solving the objective function as shown in Fig. 4 based on PSO algorithm. From this figure, it can be seen that the optimal tuning is achieved approximately through 30 iterations to obtain the minimum value for integral of time multiply squared error (ITSE) of $10.6285 \mathrm{e}-3$. The obtained optimal gains of PI controller are $K_{p}=1.48$ and $K_{i}=1667$ for D, Q, and zero-sequance controller.

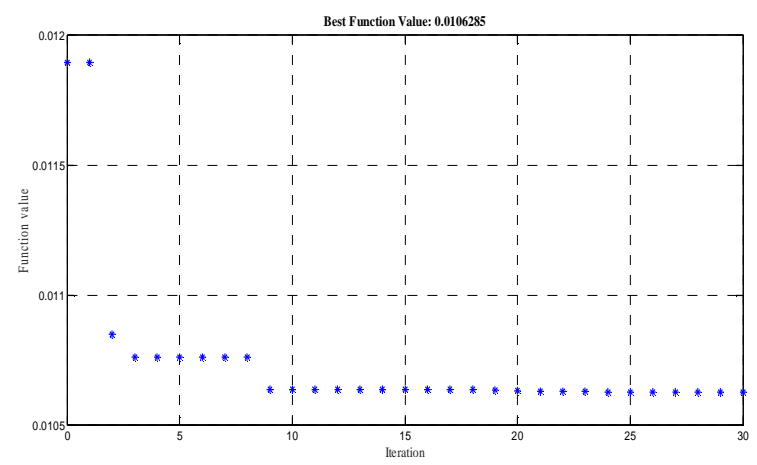

Fig. 4 objective function evaluation

\section{Dynamic Simulation Results of SSC based on PSO-PI controller}

All simulation parameters are given in the Appendix.

\section{Case1: Single -Phase Fault}

Figure 5 presents the simulation results when a phase to ground resistive fault occurs, with a fault resistance equal to $0.0117 \Omega$. The fault is produced at the high-voltage (HV) side of the distribution transformer. It starts at 20 $\mathrm{ms}$ and last for three periods of the fundamental frequency. It is observed that the SSC quickly injects the necessary voltage components to maintain the load voltage. The SSC injected voltage and the load voltage are shown in Figure 5. Per-unit variables are used and nominal powers and nominal phase to phase voltages have been selected as base magnitudes. It is observed that during the fault, the voltage in phase-A at the PCC drops down to $20 \%$ of its nominal value, while phase to ground load voltages remain almost constant during the whole event, due to the compensating actions of the SSC. Also, the figure 5 shows the $\mathrm{d}-\mathrm{q}$ components in rotating reference frame of the load voltage. Moreover, it is clear that the DC voltage is constant with high dynamic performance against the single phase fault.
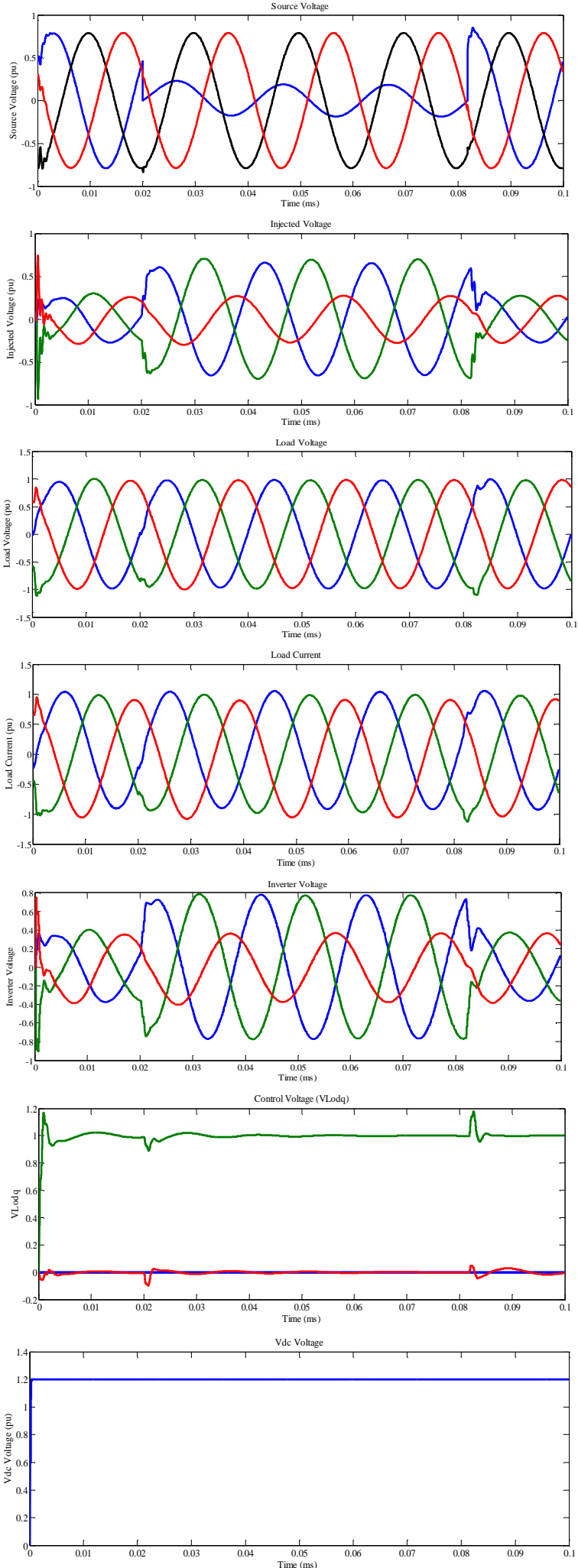

Fig. 5. Compensation of load voltage for SSC (single-phase fault and short circuit power $=20 \mathrm{pu}$ )

\section{Case 2: Double-Phase Fault}

Figure 6 presents the simulation results for the SSC system when there is a double -phase fault at the HV-side of the distribution transformer, with a fault resistance of $0.0117 \mathrm{ohm}$. The source short-circuit power is made 
equal to $20 \mathrm{pu}$ and no additional load is connected. The voltage sag starts at $20 \mathrm{~ms}$ and it is kept until $80 \mathrm{~ms}$.

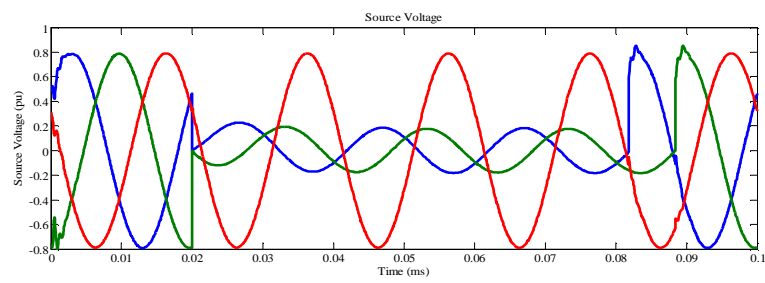

Injected Voltage

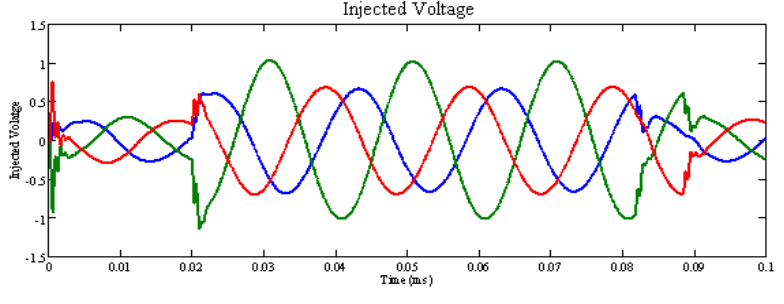

Load Vollage

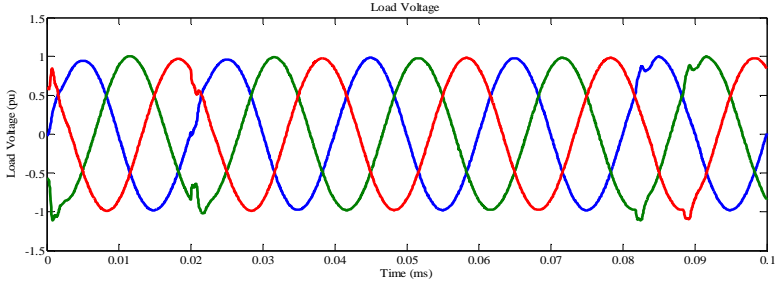

Load Current

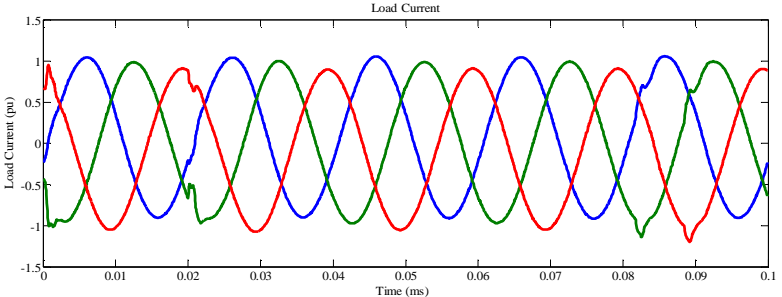
Inverter Voltage
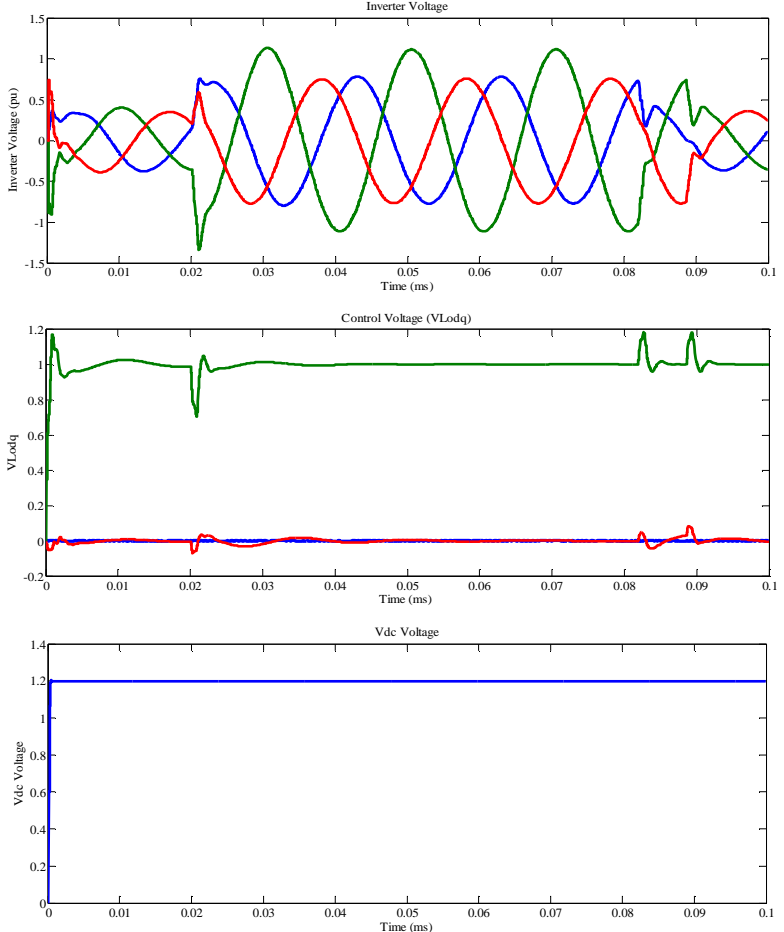

Fig.6. Compensation of load voltage for SSC (Double-phase fault and short circuit power $=20 \mathrm{pu}$ )

Figure 6 shows the voltage generated by the SSC and the compensated load voltage, respectively. As a result of $\mathrm{SSC}$, the load voltage is kept almost constant at $1 \mathrm{pu}$ throughout the simulation. This figure also shows the DC voltage and d-q components of the load voltage.

\section{Case 3: Three - Phase Fault}

Figure 7 presents the simulation results for the SSC system when there is a three-phase fault at the $\mathrm{HV}$-side of the distribution transformer, with a fault resistance of $0.0117 \mathrm{ohm}$. The source short-circuit power is made equal to $20 \mathrm{pu}$ and no additional load was connected. The voltage sag starts at $20 \mathrm{~ms}$ and it is kept until $80 \mathrm{~ms}$.
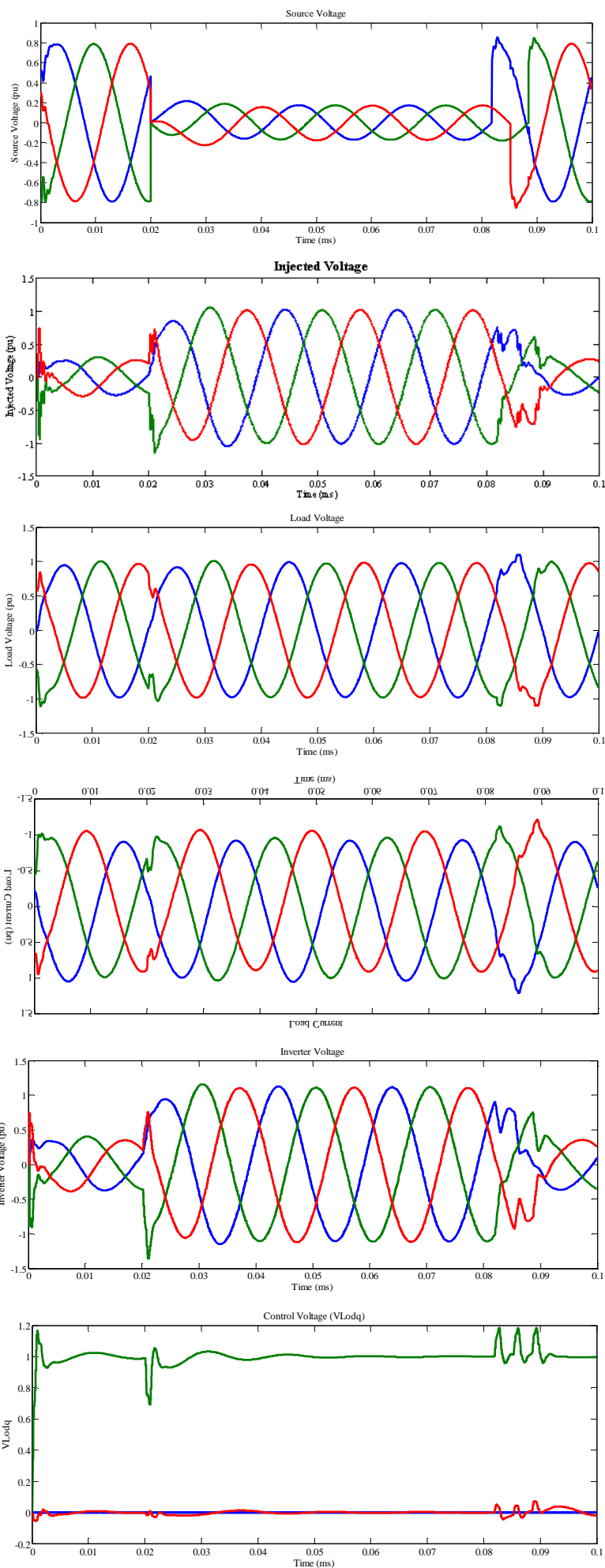


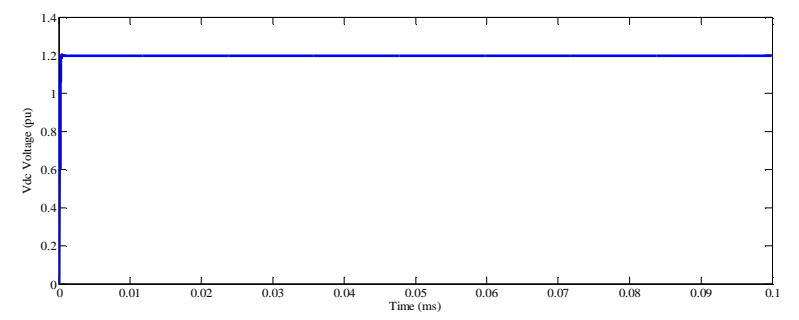

Fig. 7. Compensation of load voltage for SSC (Three-phase fault and short circuit power $=20 \mathrm{pu}$ ). Case 3 .

Figure 7 shows the voltage generated by the SSC and the compensated load voltage, respectively. As a result of $\mathrm{SSC}$, the load voltage is kept almost constant at $1 \mathrm{pu}$ throughout the simulation. Moreover, the figure shows the d-q components of load voltage and the DC voltage.

\section{Conclusions}

The study presented in this paper has been carried out by using numerical simulation. The simulation results have shown clearly the performance of the SSC for the compensation of voltage sags. The SSC has handled both balanced and unbalanced situations without any difficulties and has injected the appropriate voltage component to correct rapidly any disturbance in the supply voltage to keep the load voltage balanced and constant at the nominal value. Based on the simulation carried out, it is clear that a SSC can tackle voltage sags when protecting sensitive loads. If a voltage supply without zero-component is expected two identical controllers can be used with Park's transformation (one for the d-axis and another for the q-axis). However, a third controller (zero component) is required if situations with zero voltage component in the supply is expected.

\section{Appendix}

\section{Parameters of the SSC test system:}

- Electrical system viewed from the PCC: Short Circuit Power $=20 \mathrm{pu}$; Equivalent inductance $=157 \mu \mathrm{s}$; Equivalent Resistance $=0.007 \mathrm{pu}$;

- Distribution transformer and injected transformer: Short Circuit Power $=14 \mathrm{pu}$; Winding 1 Inductance $=$ Winding 2 Inductance $=185 \mu \mathrm{s} ;$ Winding 1 Resistance $=$ Winding 2 Resistance $=0.023 \mathrm{pu}$; Magnetizing Inductance $=63.66 \mathrm{~s}$; Magnetizing Resistance $=1500 \mathrm{pu}$

- Filter Unit : Filter Inductance $=369.5 \mu$ s; Filter Capacitance $=55.98 \mu \mathrm{s}-1$

- Inverter Circuit: Switching Frequency= $4.95 \mathrm{kHz}$; Sampling Frequency $=9.9 \mathrm{kHz}$

- Sensitive Load Apparent Power=1 pu; Power Factor $=0.93$

\section{References}

[1] C. Benachaiba, B. Ferdi "Voltage quality improvement using DVR", Electrical Power Quality and Utilization, 14, 1, 39-45, 2008.

[2] Shazly A. Mohammed, A. Cerrada, M. Abdel-Moamen, B. Hasanin, "Dynamic voltage restorer (DVR) system for compensa-tion of voltage sags, state-of-the-art review", Int. J. Computational Eng. Research, 3,1, 177-183, 2013.

[3] M. El-Gammal, A. Abou, T. ElShennawy, "Dynamic voltage restorer (DVR) for voltage sag mitigation", Int. J. Electrical and Informatics, 3, 1, 1-11, 2011.

[4] M. Bhaskar, S. Dash, C. Subramani, M. Kumar, P. Giresh, M. Kumar "Voltage quality improvement using DVR", Int. Conf. Recent Trends in Information, Telecommunication and Computing, 2010.

[5] L. Gyugy, C. Schaudar, C. Edwards, M. Sarkozi, "Apparatus and method for dynamic voltage restoration of utility distribution networks", Westinghouse Electric Corporation, Patent number 5329222, Jul.12, 1994.

[6] C. Benachaiba, B. Ferdi "Power quality improvement using DVR", American Journal of Applied Sciences 6 (3): 396-400, 2009.

[7] M. Kangarlu, S. Hosseini, A. Sadigh "Transformerless DVR topology based on multilevel inverter with reduced number of switches", IEEE Power Electronic \& Drive Systems \& Technologies Conference, 371-375, 2010.

[8] M. Abdel-Moamen, S.A. Mohamed, "Multilevel inverter based DVR for power quality improvement", Int. MiddleEast Power System Conferences, Mansoura University, Egypt, December 15-17, 2015.

[9] P. Roncero, E. Acha, J. Ortega, V. Feliu, A. García, “A versatile control scheme for a dynamic voltage restorer for power-quality improvement", IEEE Trans., Power Del., 24, 1, 277-284, 2009.

[10] P. Gonzalez, A. Cerrada "Analysis of a Neutral-point connected DVR and comparison with a conventional and a transformerless DVR", Internal report, Instituto de Investigación Tecnológica, Universidad Pontificia Comillas de Madrid, 2010.

[11] J. Basilio, S. Matos, "Design of PI and PID controllers with transient performance specification", IEEE Transactions on Education, 45, 4, 364-370, 2002.

[12] D. Xue, Y. Chen, D. Atherton, Linear Feedback control, Society of Industrial and Applied Mathematics, ISBN: 978-0-89871-638-2, 2007, ch. 6.

[13] Y. Ma, Y. Liu, C. Wang, "Design of parameters selftuning fuzzy PID control for DC motor", Int. Conf. Industrial Mechatronics and Automation, 345-348, 2010.

[14] G. Sivagurunathan, K. Jayanthi, "Fuzzy logic based self tuning of PI controller for a non linear spherical tank system", Int. Conf. Computational Intelligence \& Computing Research, 1-6, 2012.

[15] P. Wang, "PI-tuning methods based on GA", Int. Conf. Machine Learning and Cybernetics, 544-547, 2002.

[16] Z. Gaing, "A particle swarm optimization approach for optimum design of PID controller in AVR system", IEEE Trans. Energy Conversion, 19, 2, 384-391, 2004.

[17] R. Kanojiya, P. Meshram, "Optimal tuning of PI controller for speed control of DC motor drive using particle swarm optimization", Int. Conf. Advances in Power Conversion and Energy Technologies, 1-6, 2012.

[18] C. Liu, Y. Hsu, "Design of a self-tuning PI controller for a STATCOM using particle swarm optimization", IEEE Transactions on Industrial Electronics, 57, 702-715, 2010.

[19] R. Omar, N. Rahim, "Power quality improvement in low voltage distribution system using dynamic voltage restorer (DVR)", IEEE Conference on Industrial Electronics and Applications, 973-978, 2010. 